\title{
Growth inhibitory activities of extracts from peels of five species of citrus fruit on bacterial isolates obtained from rotten tomato fruits.
}

\author{
Effiom OE*, Ubi PO, Olushola TO \\ Department of Biological Sciences, Veritas University, Abuja, F.C.T., Nigeria
}

\begin{abstract}
This study was undertaken to verify the efficacies of phytochemical extracts of citrus fruit peels obtained from Citrus sinensis, Citrus reticulata, Citrus limonum, Citrus aurantifolia and Citrus vitis against isolates of tomato rot bacteria. Results of this study provide the much needed less hazardous, cheap and readily available means of controlling or managing bacterial diseases of postharvest tomato fruits to reduce the huge economic losses often incurred by tomato fruits dealers and farmers. Solvent extracts were characterized for presence of constituent active compounds, flavonoids, tannins, terpenes, cardiac glycosides, anthraquinones, saponins and alkaloids. Pseudomonas spp., Klebsiella spp. and Escherichia coli were isolated from rotten tomato fruits using McConkey, Blood and Peptone Sucrose agar media. Isolates were subjected to sensitivity test with $10 \%, 20 \%, 30 \%$ and $40 \%$ concentrations (volume by volume) of the different extracts, respectively. All the concentrations showed different degrees of growth inhibition on the test organisms. The study confirmed that phytochemical extracts from peels of citrus fruits are efficacious against tomato fruit rot bacteria and therefore have a good promise for sustainable control of bacterial rot disease of tomato fruits.
\end{abstract}

Keywords: Citrus fruits, Phytochemicals, Active ingredients, Bacterial isolates, Growth inhibition.

Accepted on May 31, 2019

\section{Introduction}

Studies conducted in different parts of the globe have revealed that over 800 million people in developing countries of the world are without adequate food supply, yet more than $10 \%$ of the food produced globally is lost due to plant diseases caused by the various plant pathogens such as viruses, bacteria, fungi, nematodes, insect pests, etc. [1]. Recent findings by Shuping and Eloff [2] from their study on the use of plant extracts to protect plants and food against fungal pathogens has confirmed the results of earlier reports (Kavitha and Satish) [3] that the crucial role which phyto-pathogens play in profitability, quality and quantity of crop production is mostly attributable to the ability of phyto-pathogens to evolve evasive and persistent mechanisms with which they evade and resist plant defences and thus cause diseases and quality losses amounting to billions of US dollars annually. The resultant drastic reduction of consumers' confidence and low profitability are manifestations of plant diseases due to these phyto-pathogens.

Until recently it was thought that organo-chemical pesticides were making positive impact in the control and management of both plant diseases and microbial contaminations in the different agricultural commodities. Unfortunately, it has now been found that the world annual crop harvest is still under serious threat by pests resulting in economic losses to the tune of nearly 300 billion US Dollars annually [4]. Another serious challenge in fruit farming has been the emergence of resistant sibling species of phyto-pathogens, besides the most worrisome hazardous effects of synthetic pesticide applications on the life-sustaining systems by residual toxicity $[5,6]$. It was the realization of the numerous undesirable attributes of chemical pesticides such as high and acute toxicity, long degradation periods, accumulation in the food chains, non-eco friendliness and pest-resistance, that led to the ban of a large number of synthetic organo-chemical pesticides in some parts of the western world in recent years [7]. It is this ban that spurred the on-going global exploration and exploitation of plants for safe, less toxic, readily biodegradable, ecosystem friendly, readily available and cheap phytochemical alternatives which can be adopted for sustainable control and management of pathogens of crop diseases such as tomato rot bacteria, fungi, etc.

Earlier studies have however, shown that besides being ecofriendly, phytochemical extracts have proved efficacious against many plant pathogens as well as enhancement of plants' productivity variables [8-15]. Even in the recent study by Abiodun et al., on efficacy of selected plant extracts in the management of tomato early blight disease caused by Alternaria solani, the application of the extracts revealed a significant influence on early blight severity, number of fruits produced, fruit length and fruit weight [16].

It is in reconsideration of these rich antimicrobial efficacies exhibited by plant extracts against food poisoning bacteria besides other potentials that several researchers across the globe are demonstrating various plant products for use against phytopathogens [17].

It is believed that exploitation of naturally available phytochemicals that have shown good promise to retard the activities of these undesirable micro-organisms may be more a realistic and ecologically sustainable method for protecting plants and their produce (fruits and seeds) against diseases [18]. 
Citation: Effiom OE, Ubi Patience O, Olushola TO. Growth inhibitory activities of extracts from peels of five species of citrus fruit on bacterial isolates obtained from rotten tomato fruits. J Agric Sci Bot 2019;3(1):12-16.

\section{Materials and Methods}

\section{Collection and processing of the citrus fruits species}

The species of citrus fruits and the tomato fruits used in this study were obtained from the open markets of Umudike in Ikwuano Local Government Area and Obehie in Ukwa West, Abia State, respectively.

The Citrus fruit species were identified by an agricultural expert in Michael Okpara University of Agriculture Umudike into Citrus sinensis (sweet orange), Citrus reticulata (tangerine), Citrus limonum (lemon), Citrus aurantifolia (lime) and Citrus vitis (grape fruits).

The fruits were first washed in clean water and dried, peeled off as thin as possible. The peels of each species were spread on white cardboard sheets on the laboratory benches and air-dried for three weeks, avoiding contamination in the process. They were then ground into powder using a cleaned and adequately sterilized grinding machine into air-tight containers ready for phytochemical extraction.

\section{Extraction of sterile phytochemicals from the citrus fruits}

To extract the volatile oils from the powdered citrus fruit materials, $100 \mathrm{~g}$ of the powder was fed into the Soxchlet extractor or apparatus (2 L), and $500 \mathrm{ml}$ of Diethyl Ether was added and mixed. The mixture was heated and the citrus oil exhaustively extracted at a temperature range of between $60-80^{\circ} \mathrm{C}$ for six hours. The extract was then left overnight at laboratory temperature $\left(37.8^{\circ} \mathrm{C}\right)$ for the remaining ether in it to evaporate. The procedure was repeated with the different powdered fruit materials prepared from peels, seeds and pulp of Citrus sinensis, Citrus limonum, Citrus aurantifolia, Citrus reticulata and Citrus vitis. The stock extracts were then preserved in an air-tight glass bottles at $4^{\circ} \mathrm{C}$.

\section{Phytochemical screening of the extracts}

The extracts were screened for active compounds, alkaloids, flavonoids, saponnins, tannins, etc., using the characterization methods for plant extracts as described by Harbone et al. [19] for alkaloids, phenolics, and tannins and Sofowora for flavonoids [20], Obadoni and Ochuko for saponins, etc [21].

\section{Isolation of bacterial species from rotten tomato fruits}

Tomato fruits obtained from the Open Market were washed, put in peptone water and incubated overnight at $37^{\circ} \mathrm{C}$ to concentrate the organism(s) if present. Sub culturing was done on McConkey, Blood agar and Peptone Sucrose Agar (PSA, for isolation of Pseudomonas spp.) the next day. The Agar plates were then incubated overnight. Pure isolates were identified as prescribed by Baker 1980 [22] (Figures 1-3).

\section{Determination of the activity of the phytochemical extracts on the test organisms}

Using the Agar well diffusion method, the activity of each phytochemical extract on the isolated bacteria was determined. Sterile pipettes were used to dispense four different concentrations $10 \%, 20 \%, 30 \%$ and $40 \%$ volume by volume, of each phytochemical extracts into the well made on nutrient

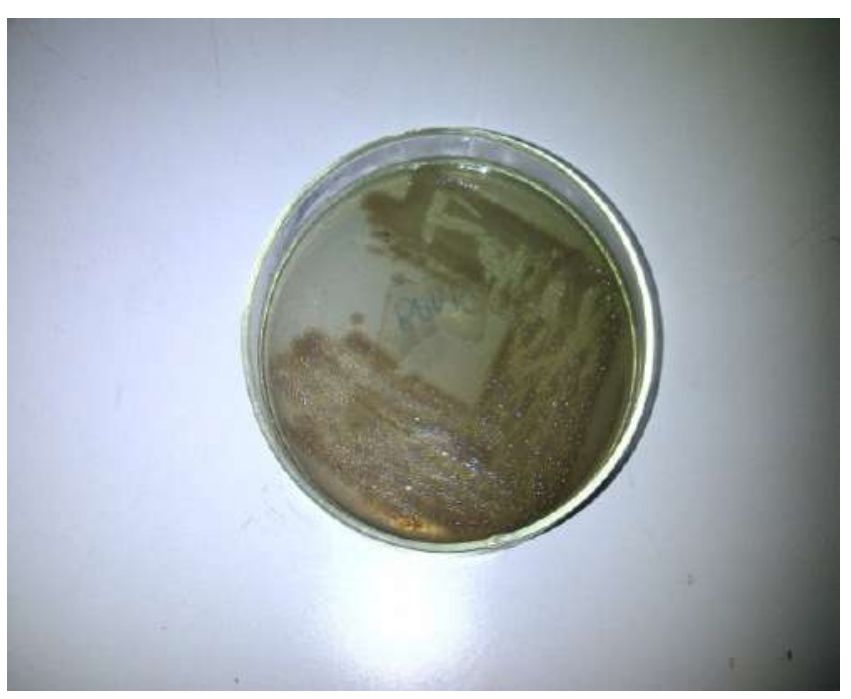

Figure1. Pseudomonas spp. on peptone sucrose agar plate.

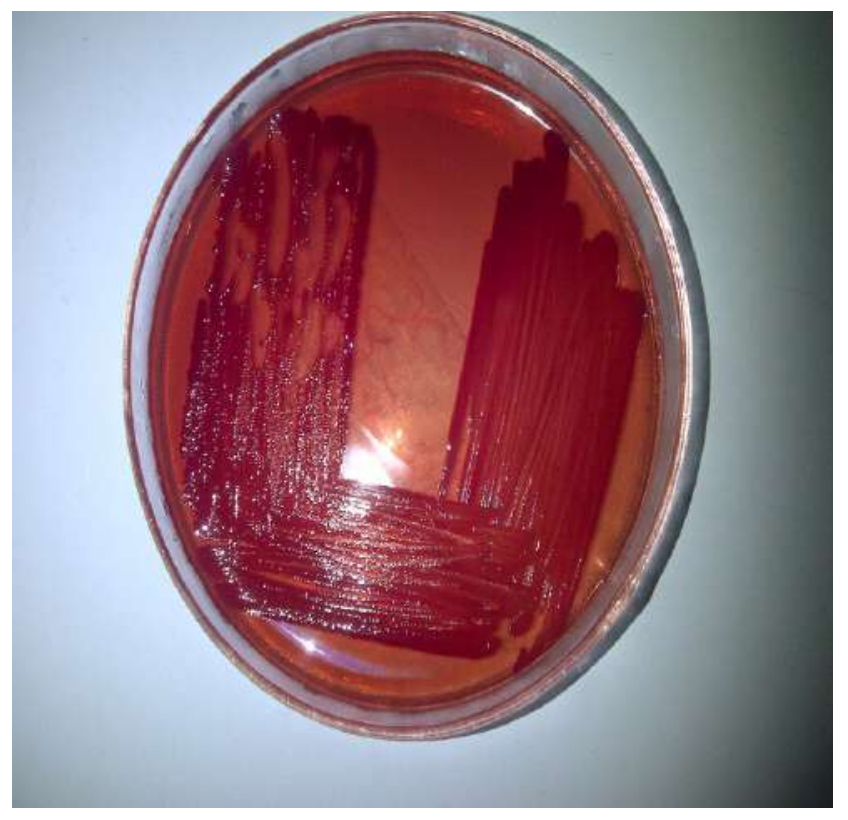

Figure 2. Escherichia coli on McConkey agar plate.

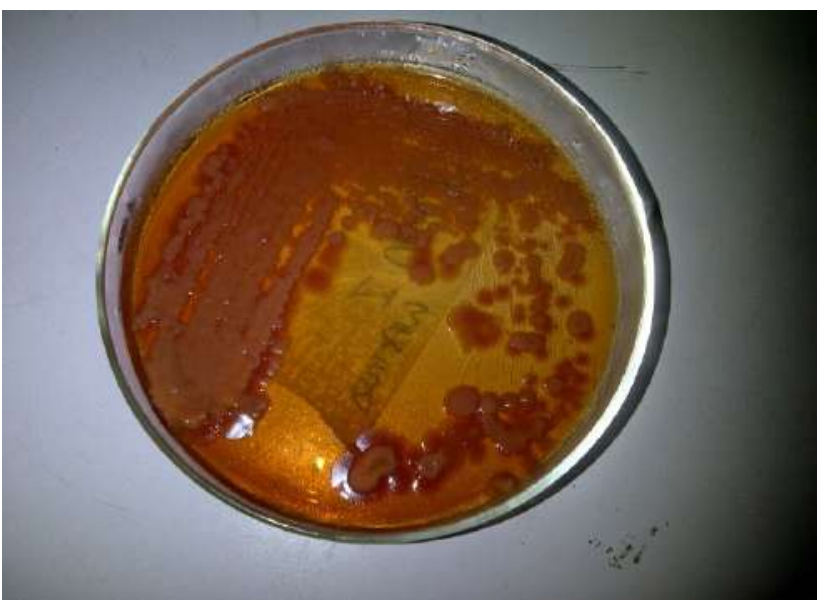

Figure 3. Klebsiella spp. on McConkey agar plate.

Agar plates upon which the organisms have been cultured. The plates were incubated overnight at $37^{\circ} \mathrm{C}$ and thereafter observed for zone(s) of inhibition. The diameter of each growth inhibition 
zone was recorded in $\mathrm{mm}$ (Table 1).

\section{Results}

The results of the qualitative analysis of the phytochemical extracts from the peels of the different citrus fruit species revealed their respective active constituents. The active compounds commonly detected in almost all the extracts were alkaloids, flavonoids, tannins, while saponins, terpenes and anthraquinones were scanty. Citrus sinensis were rich in alkaloids and flavonoids and less tannins and terpenes, while Citrus limonum had more flavonoids and tannins with alkaloids and terpenes. Similarly, Citrus aurantifolia peels contained more alkaloids and tannins with little flavonoids, cardiac glucosides, terpenes and anthraquinones. Citrus vitis and Citrus reticulata had more of flavonoids and little alkaloids, saponins and tannins. The most common active compound found in the peel extracts of all the citrus fruit species was tannins (Tables 2 and 3).

The result of the sensitivity test against the bacterial isolates showed that peel extracts from the different species of citrus fruits produced varying levels of growth inhibition for the different concentrations. The four concentrations $(10 \%, 20 \%$, $30 \%$ and $40 \%$ ) of the extract from Citrus aurantifolia (lime) tested against Pseudomonas spp. exhibited different diameters of inhibitory zones of $1 \mathrm{~mm}, 1 \mathrm{~mm}, 2 \mathrm{~mm}$ and $3 \mathrm{~mm}$, respectively.

The same extract tested against Klebsiella species, only $30 \%$ and $40 \%$ showed reasonable zones of inhibition of $2 \mathrm{~mm}$ each while for Escherichia coli $20 \%, 30 \%$ and $40 \%$ concentrations of the peel extract showed growth inhibition with inhibitory zones $2 \mathrm{~mm}, 3 \mathrm{~mm}$ and $3 \mathrm{~mm}$, respectively. In all the peel extracts tested against the three bacterial isolates only $30 \%$ and $40 \%$ concentrations produced the widest zones of growth inhibition of $2 \mathrm{~mm}$ and $3 \mathrm{~mm}$, respectively, meaning that the inhibitory effect increases with increased concentration of the peel extract.

For Citrus limonum (lemon) peel extract, 10\% concentration did not show any effect on Pseudomonas spp. and E. coli, except against Klebsiella spp. The zone of growth inhibition produced by $20 \%, 30 \%$ and $40 \%$ concentrations against Pseudomonas spp. were just $1 \mathrm{~mm}, 1.5 \mathrm{~mm}, 2-3 \mathrm{~mm}$ for $20 \%, 30 \%$ and $40 \%$ concentrations. It was only in the test against Klebsiella spp. that all concentrations of the extract of peel of Citrus limonum produced wider inhibitory zones of $2 \mathrm{~mm}, 2 \mathrm{~mm}, 2.5 \mathrm{~mm}$ and 3 $\mathrm{mm}$, respectively. For $E$. coli, only $40 \%$ concentration showed a zone of inhibition of $2 \mathrm{~mm}$.

A test performed with concentrations of Citrus sinensis (sweet orange) peel extracts against the three bacterial isolates was positive for all the organisms tested. The effect of $10 \%$ concentration was mild (with a zone of $0.5 \mathrm{~mm}$ ) against Pseudomonas spp. and Klebsiella spp. but negative against $E$. coli. Forty percent $(40 \%)$ concentration of this extract was more efficacious producing inhibitory zones of $2.5 \mathrm{~mm}, 2.5 \mathrm{~mm}$ and $3 \mathrm{~mm}$, against Pseudomonas spp., Klebsiella spp. and E. coli, respectively.

Only Pseudomonas spp. responded positively to the four concentrations levels $(10 \%, 20 \%, 30 \%$ and $40 \%)$ of the peel extract from Citrus reticulata (tangerine) producing inhibitory zones of $2 \mathrm{~mm}, 2 \mathrm{~mm}, 3 \mathrm{~mm}$ and $5 \mathrm{~mm}$ respectively. Klebsiella responded only to high concentrations (i.e., $30 \%$ and $40 \%$ ) of this particular extract, while $E$. coli showed no response at all to any of its concentrations.

The organisms did not respond to the concentrations of the peel extract from Citrus vitis (grape), except Pseudomonas spp. which produced a zone of $1.5 \mathrm{~mm}$ and $2 \mathrm{~mm}$ for $30 \%$ and $40 \%$, and $0.5 \mathrm{~mm}$ each for $40 \%$ concentration against Klebsiella and E. coli.

Table 1: Zone of inhibition $(\mathrm{mm})$ of five citrus peel extracts against test bacterial isolates on nutrient agar medium using well diffusion method.

\begin{tabular}{|c|c|c|c|c|}
\hline \multicolumn{5}{|c|}{ Bacteria and their Zones of growth Inhibition (mm) } \\
\hline Sample & Concentration & Pseudomonas spp. & Klebsiella spp. & Escherichia coli \\
\hline \multirow{4}{*}{ Citrus aurantifolia (lime) } & $10 \%$ & 1 & $\mathrm{R}$ & $\mathrm{R}$ \\
\hline & $20 \%$ & 1 & $\mathrm{R}$ & 2 \\
\hline & $30 \%$ & 2 & 2 & 3 \\
\hline & $40 \%$ & 3 & 2 & 3 \\
\hline \multirow{4}{*}{ Citrus limonum (lemon) } & $10 \%$ & $\mathrm{R}$ & 2 & $\mathrm{R}$ \\
\hline & $20 \%$ & 1 & 2 & 1.5 \\
\hline & $30 \%$ & 1.5 & 2.5 & 1.5 \\
\hline & $40 \%$ & 1.5 & 3 & 2 \\
\hline \multirow{4}{*}{ Citrus sinensis (sweet orange) } & $10 \%$ & 0.5 & 0.5 & $\mathrm{R}$ \\
\hline & $20 \%$ & 2 & 0.5 & 1 \\
\hline & $30 \%$ & 2 & 2 & 1.5 \\
\hline & $40 \%$ & 2.5 & 2.5 & 3 \\
\hline \multirow{4}{*}{ Citrus reticulata (tangerine) } & $10 \%$ & 2 & $\mathrm{R}$ & $\mathrm{R}$ \\
\hline & $20 \%$ & 2 & $\mathrm{R}$ & $\mathrm{R}$ \\
\hline & $30 \%$ & 3 & 2 & $\mathrm{R}$ \\
\hline & $40 \%$ & 5 & 2.5 & $\mathrm{R}$ \\
\hline \multirow{4}{*}{ Citrus vitis (grape) } & $10 \%$ & $\mathrm{R}$ & $\mathrm{R}$ & $\mathrm{R}$ \\
\hline & $20 \%$ & $\mathrm{R}$ & $\mathrm{R}$ & $\mathrm{R}$ \\
\hline & $30 \%$ & 1.5 & $\mathrm{R}$ & $\mathrm{R}$ \\
\hline & $40 \%$ & 2 & 0.5 & 1.5 \\
\hline \multicolumn{5}{|c|}{$\mathrm{R}=$ Resistance; Number=Diameter of the zone of growth inhibition. } \\
\hline
\end{tabular}


Citation: Effiom OE, Ubi Patience O, Olushola TO. Growth inhibitory activities of extracts from peels of five species of citrus fruit on bacterial isolates obtained from rotten tomato fruits. J Agric Sci Bot 2019;3(1):12-16.

Table 2: Result of qualitative analysis of the phytochemical extracts.

\begin{tabular}{|c|c|c|c|c|c|c|c|}
\hline Name of Sample & Alkaloids & Saponins & Tannins & Flavonoids & Terpenes & $\begin{array}{c}\text { Cardiac } \\
\text { glycosides }\end{array}$ & Anthraquinones \\
\hline C. sinensis (sweet orange) & $* * *$ & $*$ & $* *$ & $* * *$ & $* *$ & $*$ & - \\
\hline C. vitis (grape) & $* *$ & $* *$ & $* *$ & $* * *$ & $* *$ & $*$ & $*$ \\
\hline C. aurantifolia (lime) & $* * *$ & $*$ & $* * *$ & $* *$ & $* *$ & $* *$ & $* *$ \\
\hline C. limonum (lemon) & $* *$ & $*$ & $* * *$ & $* * *$ & $* *$ & $*$ & $*$ \\
\hline C. reticulata (tangerine) & $* *$ & $*$ & $* *$ & $* * *$ & $* *$ & $*$ & - \\
\hline
\end{tabular}

Table 3: Result of gram reaction and biochemical tests.

\begin{tabular}{|c|c|c|c|c|c|c|c|}
\hline Name of Sample & Alkaloids & Saponins & Tannins & Flavonoids & Terpenes & $\begin{array}{l}\text { Cardiac } \\
\text { glycosides }\end{array}$ & Anthraquinones \\
\hline C. sinensis (sweet orange) & $* * *$ & $*$ & $* *$ & $* * *$ & $* *$ & $*$ & - \\
\hline C. vitis (grape) & $* *$ & $* *$ & $* *$ & $* * *$ & $* *$ & $*$ & $*$ \\
\hline C. aurantifolia (lime) & $* * *$ & $*$ & $* * *$ & $* *$ & $* *$ & $* *$ & $* *$ \\
\hline C. limonum (lemon) & $* *$ & $*$ & $* * *$ & $* * *$ & $* *$ & $*$ & $*$ \\
\hline C. reticulata (tangerine) & $* *$ & $*$ & $* *$ & $* * *$ & $* *$ & $*$ & - \\
\hline
\end{tabular}

\section{Discussion}

The five species of citrus peel extracts used in this study showed varying but significant growth inhibitory activity against the organisms isolated from the rotten tomato fruits. Extract from peels of Citrus aurantifolia (lime) at concentrations of $30 \%$ and $40 \%$ showed a maximum zone of inhibition against Pseudomonas spp. and Escherichia coli (Figures 1 and 2, Table 1). Also, extract from peels of Citrus limonum (lemon) at a concentration of $40 \%$ showed a maximum zone of inhibition against Klebsiella spp. (Figure 3, Table 1). Extract of Citrus sinensis (orange) at a concentration of $40 \%$ showed a maximum zone of inhibition against Escherichia coli. Extract of Citrus reticulata (tangerine) at a concentration of $40 \%$ showed a maximum zone of inhibition against Pseudomonas spp. whereas Escherichia coli showed complete resistant to it. Extract of Citrus vitis (grape) on the other hand, at the same concentration (40\%) showed maximum zone of inhibition against Pseudomonas spp. Citrus reticulata was therefore the most effective against Pseudomonas spp. Similarly, Citrus sinensis and Citrus aurantifolia were the most effective against Escherichia coli, whereas Citrus limonum was the most effective against Klebsiella spp.

The results indicate that different citrus peel extracts have different antibacterial activity $[23,24]$. The observed variation in the antimicrobial activity of the different extracts may have been due to the corresponding variation in the qualitative and quantitative composition of active ingredients present in them [25-27].

The findings of this study have demonstrated the respective efficacies in growth inhibition of the phytochemical extracts against different bacterial isolates from rotten tomatoes. Extract from Citrus reticulata proved very efficacious even at lower concentrations against Pseudomonas spp., implying that it can be used in the treatment of postharvest tomato fruits against infections by Pseudomonas spp. Similarly, extracts from peels of Citrus limonum exhibited efficacy at small concentrations against Klebsiella spp. and can therefore be used in to prevent postharvest tomato fruits from infections by Klebsiella spp.
[28].

It was generally observed that the growth inhibitory activity of the phytochemical extracts increases with increased concentration of the extract.

Although Escherichia coli and Klebsiella spp. are not normally associated with tomato fruit rot disease, they may have been found in tomato fruits as a result of contaminated water used for irrigation, or organic manure used as fertilizer or as a result of washing the fruits, poor handling and storage, etc. This observation agrees with earlier findings reported by Falomir et al., which reported that fresh vegetables normally carry non-pathogenic epiphytic microorganisms arising from contamination during growth, harvest, transportation and further poor handling of the produce [29]. It was also stated that most of the reported outbreaks of gastrointestinal disease linked to fresh produce such as tomato fruits have been associated with bacterial contamination, particularly with members of the Enterobacteriaceae family of which Escherichia coli and Klebsiella belong.

\section{Conclusion}

From the result, it has become very obvious that tomato fruit rot which is affecting the post-harvest tomato fruits can be sustainably controlled using phytochemical extracts from citrus fruit species, Citrus sinensis (sweet orange), Citrus reticulata (tangerine), Citrus limonum (lemon), Citrus aurantifolia (lime) and Citrus vitis (grape fruits).

\section{References}

1. Strange RN, Scott PR. Plant disease: A threat to global food security. Annu Rev Phytopathol. 2005;43:83-116.

2. Shuping DSS, Eloff JN. The use of plant extracts to protect plants and food against fungal pathogens. A review. Afr J Tradit Complement Altern Med. 2017;14(4):120-27.

3. Kavitha HU, Satish S. Eco-friendly management of plant pathogens by some medicinal plant extracts. J Agric Tech. 2011;7(2):449-61.

4. Chandler J. Cost reduction in sit programmes using exosect auto- 
dissemination as part of area wide integrated pest management. Int J Pest Manage. 2005;47(5):257-60.

5. Campos A, Lino CM, Cardoso SM, et al. Organochlorine pesticide residues in european sadine, horse mackerel and atlantic mackerel from portugal. Food Addit Contam. 2005;22(7):642-46.

6. Bialonska D, Ramnani P, Kasimsetty SG, et al. The influence of pomegranate by-product and punicalagins on selected groups of human intestinal microbiota. Int J Food Microbiol. 2010;140:17582.

7. Ortelli D, Edder P, Corvi C. Pesticide residues survey in citrus fruits. Food Addit Contam. 2005;22(5):423-28.

8. Khallil MA. Phytofungitoxic properties in the aqueous extracts of some plants. Pak J Biol Sci. 2001;4(4):392-94.

9. Hawamdeh AS, Ahmad S. In-vitro control of Alternaria solani, the cause of early blight of tomato. J Biol Sci. 2001;1(10):949-50.

10. Saadabi MA. Antifungal activity of some Saudi plants used in traditional medicine. Asian J Plant Sci. 2006;5(5):907-9.

11.Gachomo EW, Kotchoni OS. Extract from drought-stress leaves enhances disease resistance through induction of pathogenesis related proteins and accumulation of reactive molecules. Biotech. 2008;7(2):273-79.

12.Thobunluepop P. Farming. Pak J Biol Sci. 2009;12:1119-26.

13.Latha P, Anand T, Ragupathi N, et al. Antimicrobial activity of plant extracts and induction of systemic resistance in tomato plants by mixtures of PGPR strains and Zimmu leaf extract against Alternaria saloni. Biol Control. 2009;50:85-93.

14.Moslem MA, El-Kholie EM. The effect of Neem (Azardirachta indica A. Juss) seeds and leaves extract on some plant pathogenic fungi. Pak J Biol Sci. 2009:12(14):1045-48.

15.Duru CM, Onyedineke NE. In-vitro study on the antimicrobial activity and phytochemical analysis of ethanolic extracts of the mesocarp of Voacanga Africana. Am J Plant Physiol. 2010;5(4):16369.

16.Abiodun J, Efe-Imafidon AE, Benson A, et al. Efficacy of selected plant extracts in the management of tomato early blight disease caused by Alternaria solani. Asian J Plant Pathol. 2017;11(1):4852.
17.Akinpelu DA, Aiyegoro OA, Akinpelu OF, et al. Stem bark extract and fraction of Persea americana (Mill) exhibits bactericidal activities against strains of bacillus cereus associated with food poisoning. Molecule. 2014;20(1):416-29.

18.Gottlieb OR, Borin MR, Bito NR. Integration of ethnobotany and phytochemistry: Dream or reality? Phytochem. 2002;60:145-52.

19.Harbone JB. Phytochemical methods: A guide to modern techniques of plant analysis. Chapman and Hall, London. 1973.

20.Sofowora EA. Medicinal plants and traditional medicine in Africa: Ibadan Spectrum Books Limited. 1994.

21.Obadoni BO, Ochuko PO. Phytochemical studies and comparative efficacy of the crude extracts of some homeostatic plants in edo and delta states of Nigeria. GJPSFR. 2001;8(2):203-8.

22.Baker FJ, Breach MR. Microscopic examination and staining of microorganisms. In: Medical microbiological techniques. Butterworth \& Co. Publishers Ltd., London. 1980.

23.Sokovic M, Glamoclija J, Marin PD. Antibacterial effects of the essential oils of commonly consumed medicinal herbs using an invitro model. Molecules. 2010;15(11):7532-46.

24.Effiom OE, Avoaja DA. Evaluation of minimum lethal concentrations (mlcs) of phytochemical larvicide extracts from peels, pulp and seeds of species of citrus fruits. World J App Sci Technol. 2012;4(1):13-9.

25.Gibbons S. Plants as a source of bacterial resistance modulators and anti-infective agents. Phytochem Rev. 2005;4(1):63-78.

26.Kumar KA, Narayani M, Subanthini A, et al. Antimicrobial activity and phytochemical analysis of citrus fruit peels. Utilization of fruit waste. Int J Eng Sci Technol. 2011;3(6):5414-20.

27.Akanda KM, Mehjabin S, Parvez M. Antibacterial activity of different citrus fruits. J Health Sci Med Res. 2017;2(2):25-32.

28.Effiom OE, Avoaja DA, Ohaeri CC, et al. Laboratory assessment of the bio-efficacy of the phytochemical extracts from peels, pulp and seeds of citrus fruit species against Anopheles gambiae and Anopheles funestus. Nigerian J Parasitol. 2014;35(1-2):123-32.

29.Falomir MP, Gozalbo D, Hortensia R. Coliform bacteria in fresh vegetables: From cultivated lands to consumers. Curr Res Technol Edu topics App Microbiol Microbial Biotechnol. 2010;2:1175-81.

\section{${ }^{\star}$ Correspondence to:}

Okoi Enang Effiom

Department of Biological Sciences, Veritas

University, Abuja, F.C.T., Nigeria

E-mail: drolivereffiom@gmail.com 